\title{
Correction to: The often-overlooked elements of \#PatientFirst imaging: Focus on optimal quality, including up-to-date protocols and equipment
}

\author{
Randall C. Thompson ${ }^{\mathrm{a}}$ \\ a St. Luke's Mid America Heart Institute, Kansas City
}

doi: $10.1007 / \mathrm{s} 12350-021-02898-y$

\section{CORRECTION TO: JOURNAL OF NUCLEAR CARDIOLOGY HTTPS://DOI.ORG/10.1007/S12 350-021-02836-Y}

This article was updated to correct the author's affiliation. The original article has been corrected.
Publisher's Note Springer Nature remains neutral with regard to jurisdictional claims in published maps and institutional affiliations.

The original article can be found online at https://doi.org/10.1007/ s12350-021-02836-y.

Reprint requests: Randall C. Thompson, St. Luke's Mid America Heart Institute, Kansas City; rthompson@saint-lukes.org

J Nucl Cardiol 2022;29:894.

1071-3581/\$34.00

Copyright $(\subset 2021$ The Author(s) under exclusive licence to American Society of Nuclear Cardiology 